\title{
Design of Automatic Disinfection System based on MSP430 Single-chip Microcomputer
}

\author{
Yan Honglai \\ Xi 'an International University, Xi ' an 710077, Shanxi
}

Keywords: MSP430 Microcontroller; intelligent control; self-sterilizer; self-heating

\begin{abstract}
This design is based on MSP430 single-chip microcomputer feeding room automatic disinfection system. This paper mainly studies the selection of sensor, the filtering and optimization of sensor output signal, the selection of main control processor and the design of peripheral circuit, the design of power supply system and the low power consumption processing. This design has the timing of the feeding room disinfection, at the same time has the automatic control temperature and the automatic exhaust ventilation function.
\end{abstract}

This design is based on single-chip MSP430 of the House automatic disinfection system with the ability to regularly disinfect the breeding room, at the same time with automatic control temperature and automatic exhaust ventilation function.

\section{System total design}

The disinfection system of feeding house based on MSP430 is an intelligent control system controlled by single chip microcomputer. When the user provides electricity and starts working, the MCU will use the temperature and humidity sensor to collect the temperature and humidity information of the feeding room. In the aspect of disinfection design, a clock DS1302 is used to control the time information of an entire system, and then through its timing function to control the turn of the purple led or off. Because the voltage of purple light LED is relatively high, in this design, the use of single-chip machine through the relay to drive the method. The master control chart is shown in Figure 1.

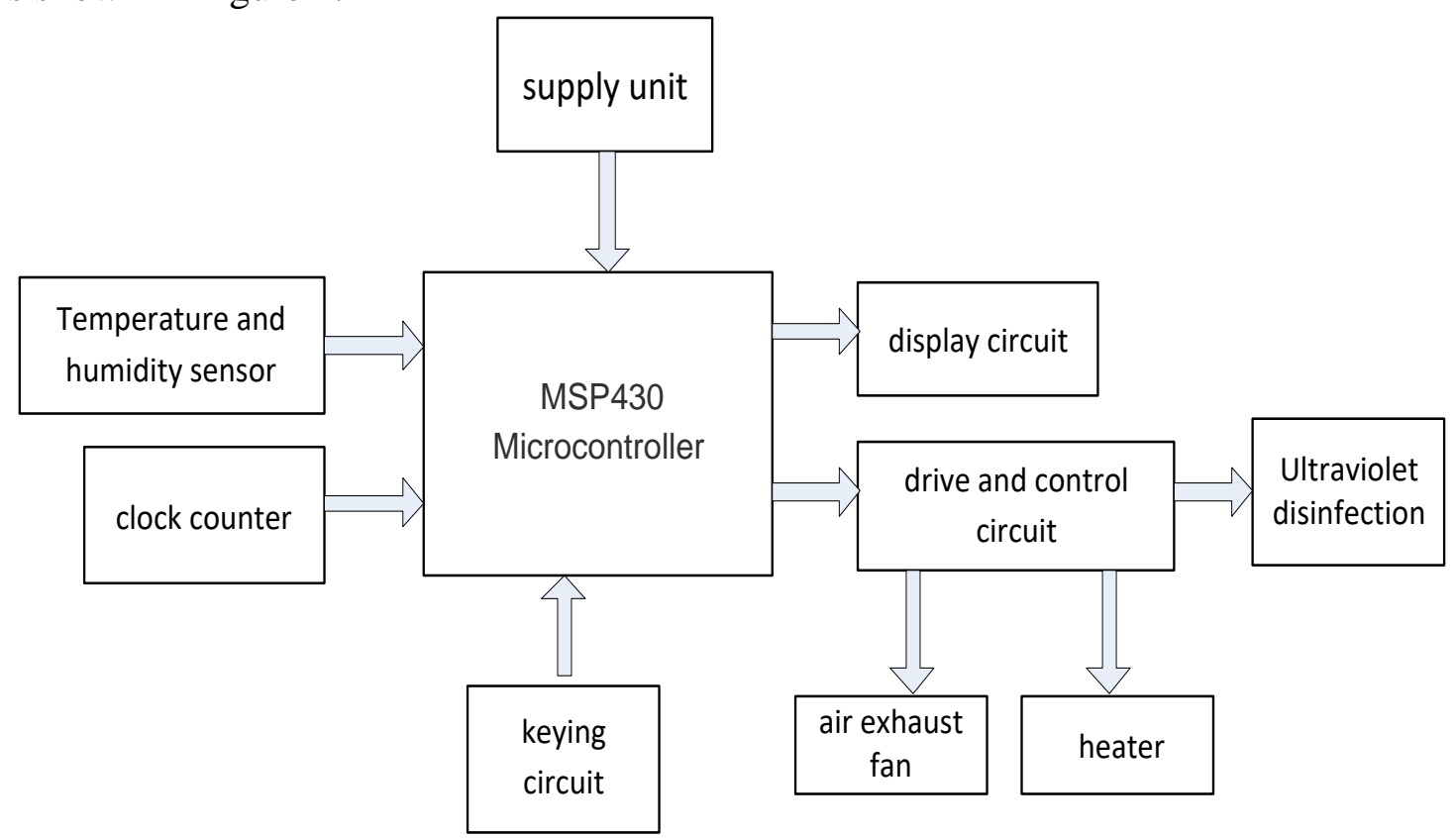

Figure 1.feeding room system structure diagram 


\section{System hardware design and important module design}

\subsection{Selection and design of disinfection module}

This system is based on MSP430 House system design, an important module is able to achieve the disinfection of the breeding room. This design through the comparison of disinfection equipment on the market, and a combination of various factors, the final selection of purple led in the form of disinfection equipment (with LED diode instead). In fact, the diagram is shown in Figure 2.

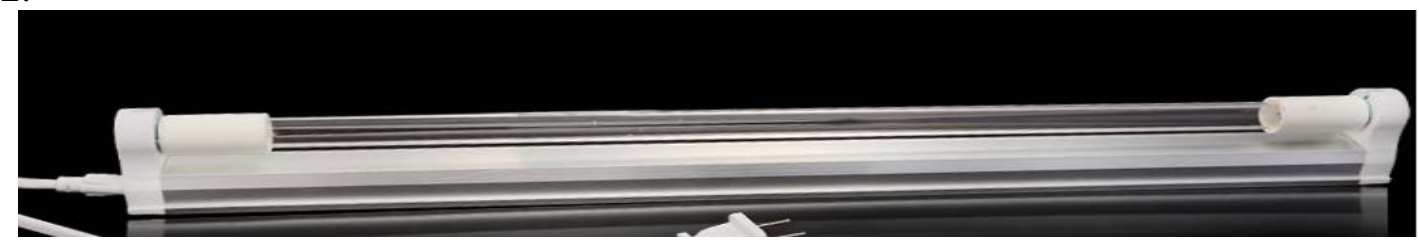

Fig. 2 Purple LED physical diagram

\subsection{Design of driver module}

In this design, we should use single chip microcomputer to the large voltage of the purple light led to achieve a control effect, because the operating voltage of the purple light LED is relatively high, so the use of relay driven method, its workflow is through the single-chip P1.7 pin to control. Single-chip microcomputer by driving a NPN type of transistor, and then using the transistor switch conduction performance and current amplification performance, and then MP430 can be through the IO interface to control the relay drive purple light LED work. At the same time, the exhaust fan and heater in this circuit are working with high voltage, so when it is used, the driving mode is the way to drive using relays. The circuit is shown in Figures 3, 4, and 5.

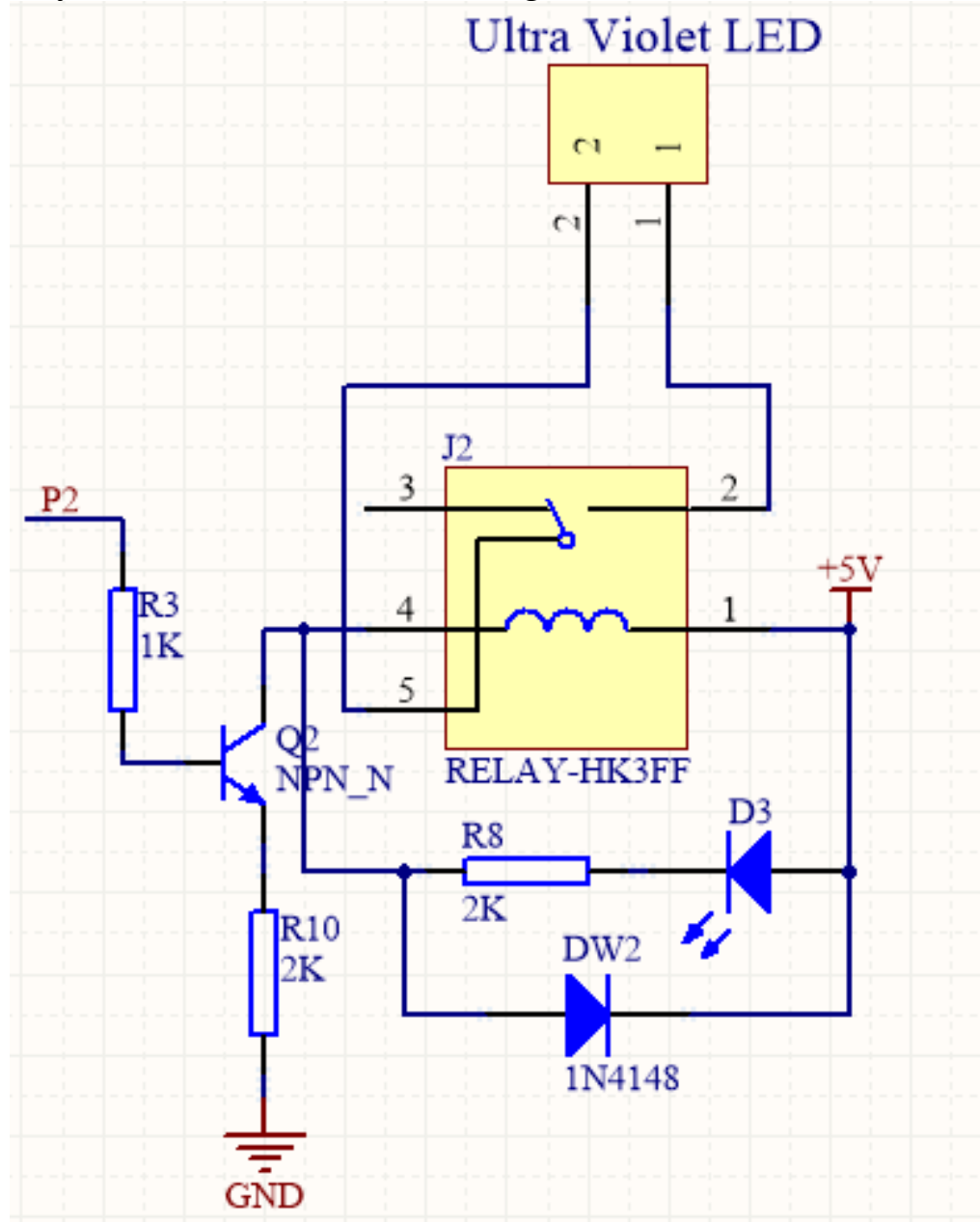

Fig.3 Relay Drive Purple light LED module design 


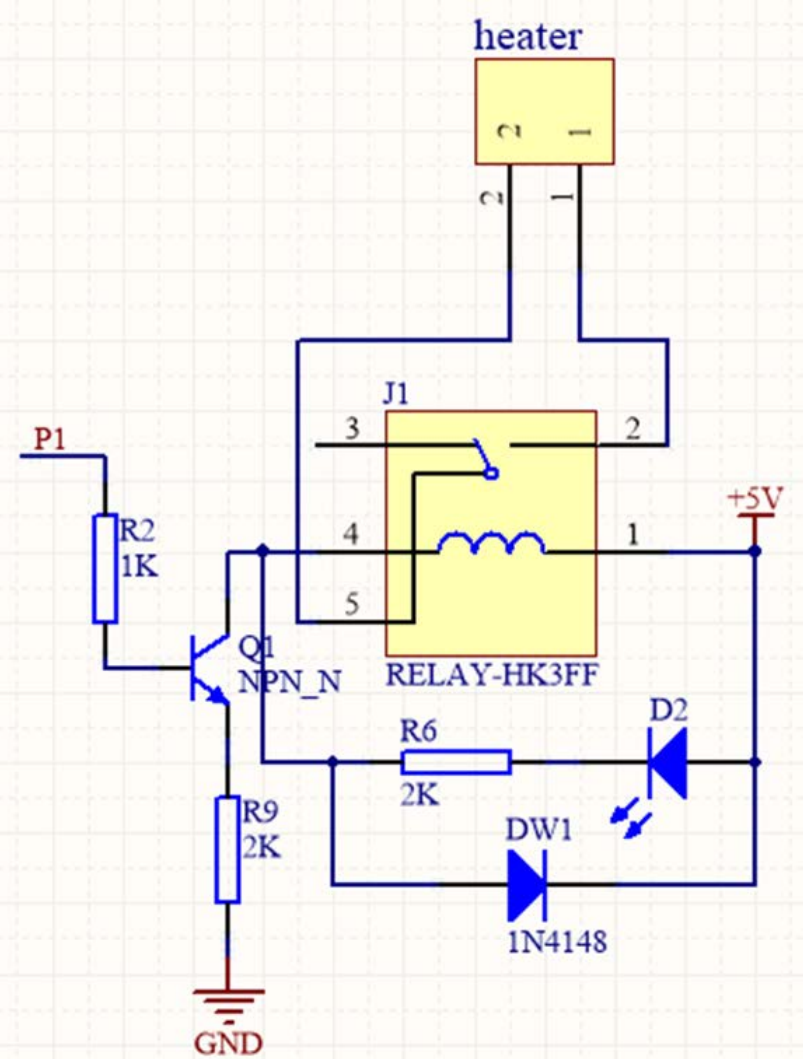

Fig. 4 design of Relay Drive heater module

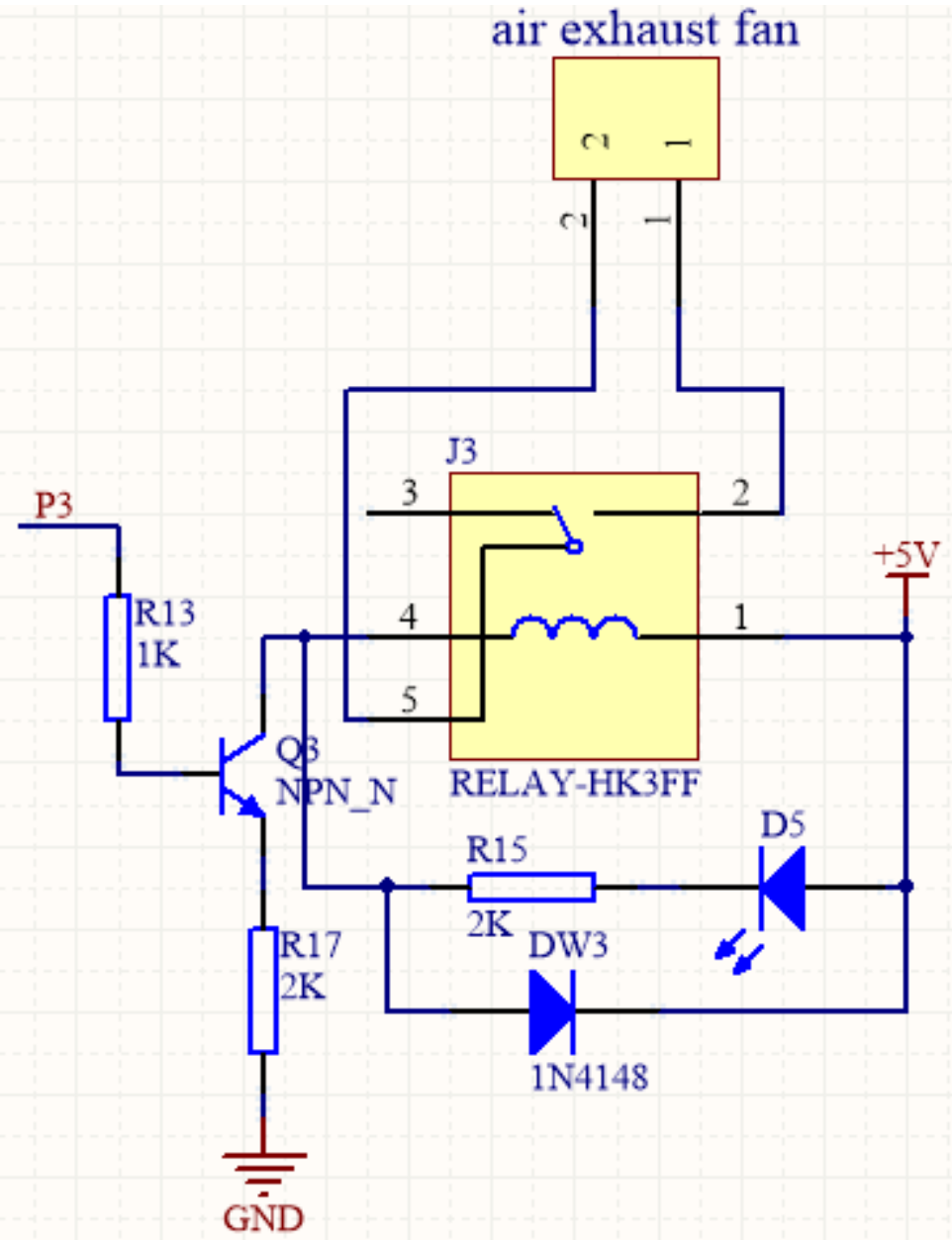

Fig. 5 Design of exhaust fan module using relay 


\section{Temperature and humidity module design}

In the automatic disinfection system of the feeding room, two important parameters are temperature and humidity. This design, the use of two-in-a test temperature and humidity sensor module, using the temperature and humidity sensor DHT11 model. The hardware circuit design is shown in Figure 6.

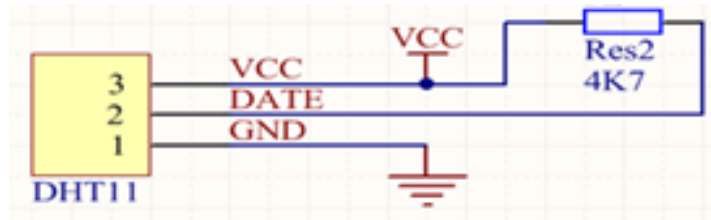

Fig. 6 Temperature and humidity sensor circuit design

DHT11 digital temperature and humidity sensor is a very accurate digital sensor, its interior has a calibrated digital signal related circuit design, its output signal is very accurate, is a temperature and humidity composite sensor, its precision is very high, and has a good circuit design.

\section{Liquid crystal display circuit design}

In this design, in order to increase the aspect and ease of human-computer interaction, a liquid crystal display module is added, using 1602. The use and operation of LCD 1602 is very convenient and feasible, he contains 8 data related data lines, but also for the control of 3 control lines, so that a total of 11 IO port lines, so that the microcontroller in the operation, only need 1 IO port to operate and process the liquid crystal. One thing to note about the use of LCD 1602 is the VO port. When this pin VO is connected to a high voltage, the minimum contrast of the liquid crystal is not very clear, but when the low power is connected, the contrast of the liquid crystal will be very high. Therefore, in this design the use of a potentiometer can adjust the voltage, so that the voltage of this interface can be adjusted to optimize the display, enhance the user's feelings. This is shown in Figure 7.

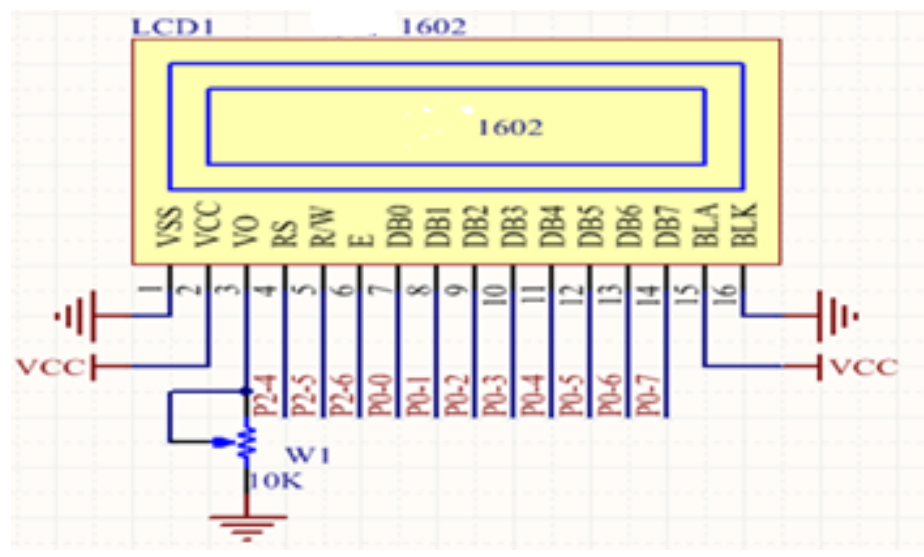

Fig.7 schematic diagram of liquid crystal circuit

\section{Key circuit design}

In this design, because of the need for people to carry out key operation, so the design of the key circuit. As shown in Figure 8, when the key is pressed, the IO of the MCU is pulled down, at which point the microcontroller recognizes the key press, that is, executes the relevant program to run. 


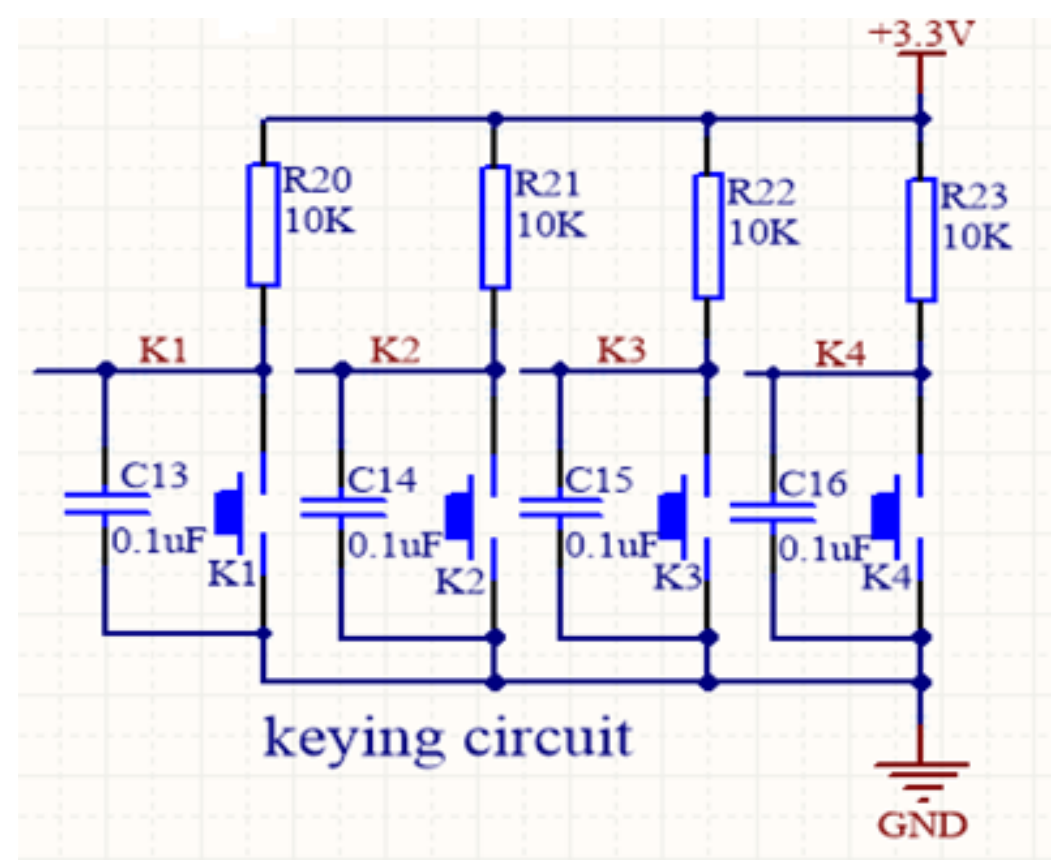

Fig. 8 Key circuit design

\section{Conclusion}

By finding and reading the relevant literatures about the automatic disinfection system of feeding house based on MSP430 at home and abroad, on the basis of the existing technology, the overall design of the system scheme, the realization of module function distribution, the combination and debugging of the system, and so on, can realize the collection and display of the temperature and humidity information of the breeding room, Can realize the collection and display of the house time information and control, can achieve automatic disinfection, exhaust, heating.

\section{References}

[1] Zhao Wenxiu. Some problems of common system in MSP430 [J]. 2008-4

[2] Zhang chi, Common module design for MSP430 [J]. 2006-27-4

[3] Chen Ming, 8051 SCM, curriculum design, training materials, [M], Singapore: University press, September 2003

[4] JIANG Lin, PU Dun, ZHEN Maquzong, XIAO Wei, LIU Yan-liang, SUO Langbianba, Design and implementation of multi-function photovoltaic charging Tibetan table lamp based on solar energy, 2011.

[5] V. Yu. Teplov. A. V. Anisimov. Thermostatting System Using a Single-Chip Microcomputer and Thermoelectric Modules Based on the Peltier Effect [J], 2002.

[6] Johannes Wandt, Peter Jakes, Josef Granwehr, Rüdiger A. Eichel, Hubert A. Gasteiger. Quantitative and Time Resolved Detection of Lithium Plating on Graphite Anodes in Lithium Ion Batteries [J]. Materials Today, 2017 